\title{
Mechanical Properties and Texture Evolution of High-Carbon Steel Wires During Wire Drawing: Strand Manufacturing
}

\author{
A. Kisrane-Bouzidi ${ }^{*}$, M. Zidani ${ }^{1,2}$, M.C. Nebbar ${ }^{1,3}$, T. Abid ${ }^{4}$, \\ A.L. Helbert ${ }^{5}$, F. Brisset ${ }^{5}$ and T. Baudin ${ }^{5}$ \\ ${ }^{1}$ Université Mohamed Khider Biskra, Laboratoire de Génie Énergétique et Matériaux, \\ Faculté des Sciences et de la Technologie, Biskra 07000 Algérie. \\ Université de Batna 02, Faculté de technologie, BP 53, 05078 Fésdis, Algérie \\ ${ }^{3}$ Centre de Recherche Scientifique et Technique en Analyses Physico-chimiques \\ (CRAPC)- BP 384, Bou-Ismail, RP 42004, Tipaza, Algérie. \\ ${ }^{4}$ Tréfisoud - ZI, BP. 09 El Eulma - Sétif-Algérie. \\ ${ }^{5}$ Institut de Chimie Moléculaire et des Matériaux d'Orsay, UMR CNRS 8182, \\ SP2M, Université Paris-Sud, 91405 Orsay Cedex, France \\ *ahmedd.kisrane@gmail.com
}

Keywords: High-carbon steel, Wire drawing, Strand, Texture, Mechanical properties.

\begin{abstract}
In this paper, the evolution of texture in the ferrite phase and mechanical behavior of colddrawn pearlitic steel wires produced for strand manufacturing at Trefisoud company was investigated. Wire drawing induces the development of dislocation density, reduction of interlamellar spacing and the refinement of grains size which leads to a strong hardening of the wires. That explains the increase of the tensile strength from $1242 \mathrm{MPa}$ to $2618 \mathrm{MPa}$ with higher deformation. Also, the cementite lamellae are rotated toward the drawing axis and the thickness of lamellae further decreases when strain level increases, this phenomenon leads to a somewhat fibrous structure. The quantitative analysis obtained by EBSD data shows the development of a strong ( $<110>/ / \mathrm{ND})$ texture of the ferrite phase leading to a structural transformation from isotropic to anisotropic.
\end{abstract}

\section{Introduction}

Cold drawing pearlitic steel wires of eutectoid or hyper-eutectoid compositions have been studied extensively as a topic of considerable amounts of scientific researches over the past several decades because of their unique combination of very high strength, torsional and bending strength, reasonable ductility and acceptable level of toughness aside from the other inherent specific material properties such as corrosion resistance, weldability, and machinability [1-6]. They are largely used for many reliability-critical applications including strands, suspension bridge cables, civil engineering and construction, automotive tyre cord, engineering springs, railroad rails, and many other industries [2,7$11]$.

The drawn wires are typically produced by wire drawing technique, which is one of the most frequently applied techniques in the wire manufacturing industry. This process is one of the oldest metal forming processes $[8,12]$, During the wire drawing operation, the steel wires are cold drawn for cross-sectional reduction by passing through multiple stages of dies $[9,13,14]$. wire drawing improves the mechanical properties of the wires. This has been attributed on the one hand, to the development of dislocation density, the re-orientation of cementite lamellae into the drawing direction. On the other hand, the reduction of interlamellar spacing and the refinement of grains size. 
The strength of the steel wires also increased during wire drawing. Embry and fisher. [15] proposed that strengthening of wires followed the Hall-Petch relationship which suggests that the strength can be increased by reducing lamellar spacing and by increasing strain [16]. Recently, it has been found that the tensile strength of heavily cold drawn pearlitic wires can be reached by $7 \mathrm{GPa}$ at higher deformation [3,17,18]. Also, numerous investigations [2,8,12,15,19-21] have reported that the cold drawing pearlitic wires acquires a textured fibrous microstructure, especially the majority fiber texture $\langle 110\rangle$ in the ferrite phase. As drawing proceeds, this fiber developed and become intensified at higher deformation [15].

In this work, we investigated the mechanical behavior and texture evolution of cold-drawn pearlitic steel wires produced for strand manufacturing, which were drawn from medium strain to high strain. Also, the correlation between microstructure and mechanical properties of the pearlitic steel wires during wire drawing is discussed.

\section{Experiments}

\subsection{Material and Methods}

The present work was carried out on hyper-eutectoid steel wire intended for the manufacturing of strands received by Trefisoud company (The National Company of Wire Drawing and Manufacture of Welding Products, Algeria). This material was commercially produced fully pearlitic steel in the as-rolled condition and was selected as the reference material (wire rod) in the present investigation. The detailed chemical composition of the steel (in weight \%) is given in Table1.

Table1. Chemical composition of high-carbon steel wire rod used in this work.

\begin{tabular}{cccccccccccc}
\hline Composition & $\mathrm{C}$ & $\mathrm{Mn}$ & $\mathrm{Si}$ & $\mathrm{P}$ & $\mathrm{Cr}$ & $\mathrm{Ni}$ & $\mathrm{S}$ & $\mathrm{V}$ & $\mathrm{Cu}$ & $\mathrm{Mo}$ & $\mathrm{Co}$ \\
\hline $\mathrm{Wt} \%$ & 0.89 & 0.63 & 0.32 & 0.013 & 0.31 & 0.024 & 0.012 & 0.004 & 0.011 & 0.002 & 0.006 \\
\hline
\end{tabular}

The initial perform for wire drawing was in the form of a circular rod of diameter $(11.00 \mathrm{~mm})$. This rod was cold drawn to the final wire by eight paths through several dies at room temperature under the dry condition with an average area reduction of $20 \%$ in each pass machine. This process resulted in wire with a final diameter of $(4.03 \mathrm{~mm})$. During each stage the true strain is calculating by equation (1):

$$
\varepsilon=2 \ln \left(d_{0} / \mathrm{d}\right)
$$

Where $\mathbf{d}_{\mathbf{0}}$ is the initial diameter, and $\mathbf{d}$ the diameter of the wire after successive drawing.

For this investigation, a various of drawn wires specimens were chosen, but results of only 2 strain levels are presented for the current study, (i.e. $\varepsilon=1.16$ medium strain and $\varepsilon=2.01$ high strain). The parameters characterizing the deformation of specimens are given in Table2.

Table2. Information about specimens investigated in this study, wire diameter $\mathbf{d}_{\mathbf{i}}$, strain level $\varepsilon$

\begin{tabular}{ccc}
\hline Specimens & $\mathbf{d}_{\mathbf{i}}[\mathbf{m m}]$ & Strain level $\boldsymbol{\varepsilon}$ \\
\hline Wire rod & 11 & 0.00 \\
Wire draw 1 & 6.15 & 1.16 \\
Wire draw 2 & 4.03 & 2.01 \\
\hline
\end{tabular}


The Microstructure features of specimens were examined along the longitudinal wire section after conventional mechanical polishing with SiC papers from 120\# to 4000\# grit and final thinning was carried out by the use of a tissue paper with the addition of diamond paste. This mechanical polishing followed by etching using a 4\% Picral solution (4g picric acid and 96\% ethanol). The microstructures were observed through a (VEGA3 TESCAN) scanning electron microscope (SEM) coupled with modern electron optics based on a unique four-lens wide field optics ${ }^{\mathrm{TM}}$ design with a proprietary intermediate lens. The accelerating voltage was $20 \mathrm{kV}$. Microhardness measurements were performed on the longitudinal wire section using Vickers microhardness tester with an applied load of (500g). Tensile tests of specimens were performed at room temperature using a universal material testing machine at Trefisoud company. Tensile strength (TS), yield strength $(0.2 \%$ proof stress) and elongation were directly determined from their true stress-strain curves. The same specimens were analyzed by SEM-EBSD on a Zeiss 940 SEM with a tungsten filament equipped with an OIM ${ }^{\mathrm{TM}}$ camera (Orientation Imaging Microscopy) software. This analysis was performed in the standard manner.

\section{Results and Discussion}

\subsection{Microstructure Evolution}

Figures 1(a-b) show the micrographs obtained from the longitudinal section of the wires at different levels of wire drawing. The microstructure of the initial wire (wire rod) is composed of fully pearlitic colonies with different sizes of grains (fig. 1a). Also, the cementite lamellae in pearlitic colonies are randomly oriented and do not have a strong tendency, on the contrary it takes various ways. Zidani et al. [12] have noted that this random orientation of the cementite lamellae leads to a heterogeneous microstructure in the section of wires $[12,19,20]$.

During cold drawing, the pearlite colonies without a clear preference stretched and aligned along the drawing axis, this elongation is more clear when the strain level increases (fig. 1b), Zhang et al. [22] and He et al. [23] have observed that during wire drawing the cementite lamellae are rotated toward the drawing axis and the thickness of lamellae further decreases when strain level increases, this phenomenon leads to somewhat fibrous structure [8,19,24]. Moreover, the wire drawing had a strong influence on the interlamellar spacing. As drawing strain increased the interlamellar spacing of cementite decreased and this is clear in the wire deformed to the higher strain level $(\varepsilon=2.01)$. Embury and Fisher. [15] have already confirmed this study with a simple relationship between lamellae width and true strain [3]:

$$
r_{\varepsilon}=r_{0} \exp (-\varepsilon / 2)
$$

This relationship has a simple read which was the interlamellar spacing is reduced proportionally to the wire diameter during the wire drawing process.

The grains size evolution of the drawing wires is illustrated in Fig. 2b-c, the microstructure is taken by the EBSD technique. The EBSD data were then treated with the OIM Analysis software, developed by the EDAX company. The cleanup procedure used to analyze the data was a Grain Dilation (one iteration, minimum grain size $=5$, grain tolerance angle $=5$ ) followed by a Grain CI Standardisation (same parameters). Also, only the points with a confidence index higher than 0.05 were taken into account [25]. Figure $2 b$ shows the grain color map of the wire rod $(\varepsilon=0.00)$, in this Map all of the grains have a random distribution and the grains have different size with different diameter, on the other hand, Figure $2 \mathrm{c}$ shows the grain color map of the deformed wire $(\varepsilon=2.01)$. It can be seen clearly 
that after wire drawing there is a redistribution of grains along the wire drawing direction and the size of the grains is refined and became smaller.

Figure $2 \mathrm{a}$ presents the curve of grain size (diameter) in area fraction. The results of the curve reinforce the previous observation (Fig. 2b-c). Whereas, it can be seen that for the starting material 10 to $11 \%$ of area fraction of grains has a diameter varying between 16.19 and $20.06 \mu \mathrm{m}$. While 11 to $13 \%$ of area fraction of grains has only a diameter varying between 3.27 and $5.08 \mu \mathrm{m}$ for the final drawing wire. Finally, we can say that the increase of the wire drawing is accompanied certainly with the reduction of the grain size.
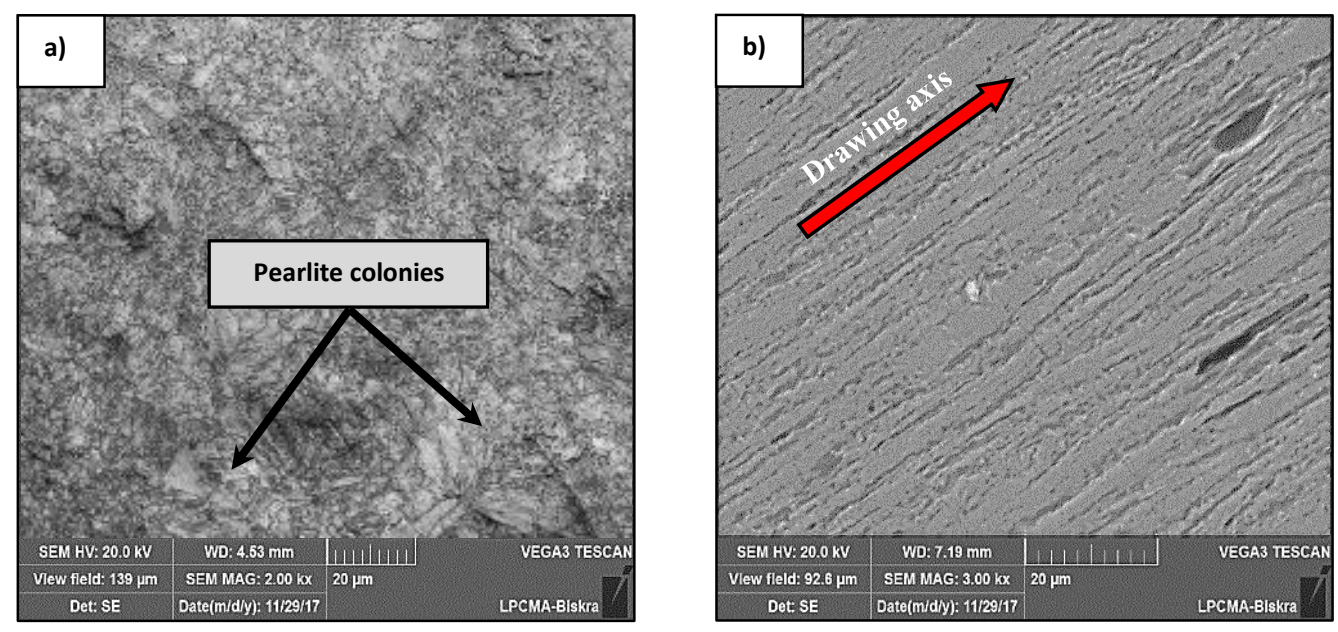

Fig. 1 SEM micrographs of a longitudinal section of cold drawing steel specimens at different strain levels: a) $\varepsilon=0.00$ (wire rod) b) $\varepsilon=2.01$
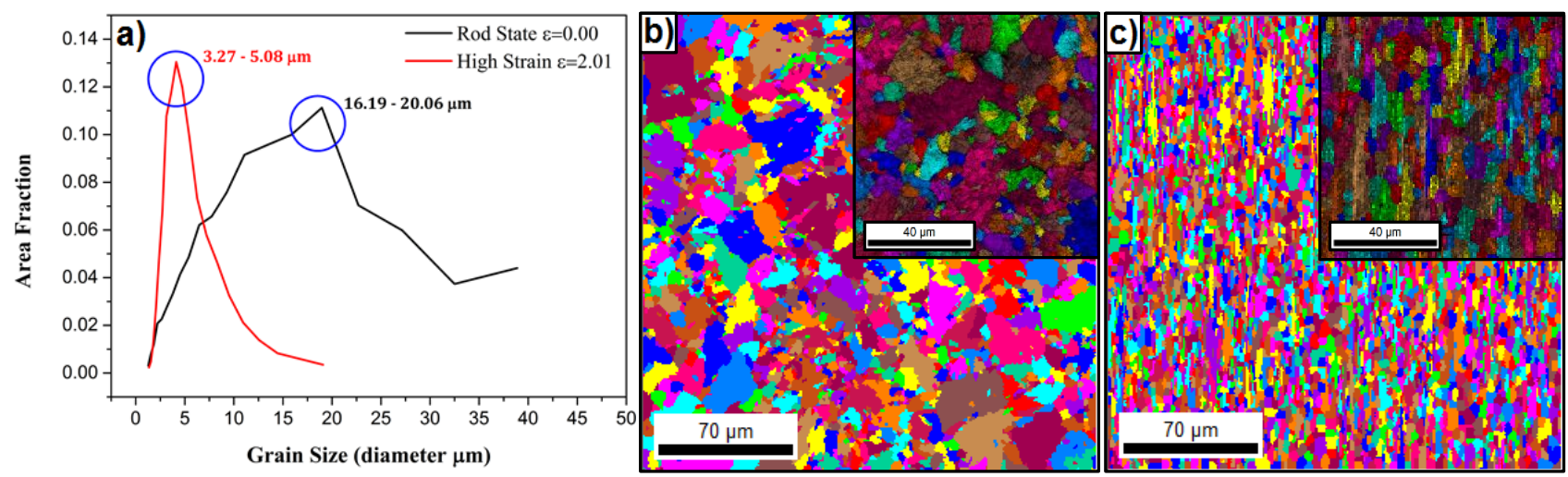

Fig. 2 a) Grain size curve, b) Unique grain color EBSD map of the wire rod: $\varepsilon=0.00$, and c) Unique grain color EBSD map of the wire drawn (high strain): $\varepsilon=2.01$

\subsection{Mechanical Properties}

To investigate the influence of the wire drawing process on the mechanical properties of the pearlitic steel wires we established a tensile test at room temperature for the specimens at a different stage of wire drawing (fig. 3). Thus, a microhardness measurement of the specimens was performed. The detailed results are listed in table 3. 
Table3. Mechanical properties of the drawing wires with a different stage of strain

\begin{tabular}{ccccc} 
Strain level $\boldsymbol{\varepsilon}$ & \multicolumn{4}{c}{ Mechanical properties } \\
\cline { 2 - 5 } & $\begin{array}{c}0.2 \% \text { Yield strength } \\
\sigma_{Y S}[\mathrm{MPa}]\end{array}$ & $\begin{array}{c}\text { Tensile strength } \\
\sigma_{\mathrm{TS}}[\mathrm{MPa}]\end{array}$ & $\begin{array}{c}\text { Elongation } \\
\text { El [\%] }\end{array}$ & $\begin{array}{c}\text { Microhardness } \\
{[\text { Hv 0.5] }}\end{array}$ \\
\hline$\varepsilon=0.00$ & 940 & 1242 & $9-10$ & 350 \\
$\varepsilon=1.16$ & $1410 \pm 5$ & 1655 & 4.5 & 375 \\
$\varepsilon=2.16$ & 2560 & 2618 & $1.5-2$ & 480 \\
\hline
\end{tabular}

Figure 3 shows the tensile test curve of the wire rod as well as the drawing wires. It is observed that the tensile strength increases with the increase of strain level. The tensile strength of the wire rod ( $\varepsilon=0.00$ ) was measured and found it be around $1242 \mathrm{MPa}$. This tensile strength is increased largely and reached $2618 \mathrm{MPa}$ at higher strain $(\varepsilon=2.01)$. Indeed, the ductility is reduced with the increase of the wire drawing. It can be seen that there is almost no plastic deformation at the final wire. It is well known that work hardening rate is dependent on tensile strength and deformation, and this leads certainly to the rising of work hardening rate as a function of drawing strain [16,26,27].

Microhardness, tensile strength and $0.2 \%$ yield strength of the steel specimens are plotted as a function of the strain levels in fig. 4. As pointed out by Goto et al. [11] and Langford. [28] in their studies the values of mechanical properties rise exponentially with the increase of strain level. However, as drawing wire increases the elongation decreases and recorded very low values especially in the final wire as shown in fig. 5.

Furthermore, the curve of microhardness as a function of strain level (fig. 4) shows that the wire drawing affects the microhardness. It can be seen that the microhardness increases progressively with strain level. This was attributed on the one hand to the dislocation storage and the development of dislocation density, the re-orientation of cementite lamellae into the drawing direction and the reduction of interlamellar spacing. On the other hand to the refinement of grains size as is demonstrated previously in grain size curve in fig. $2 \mathrm{a}[8,9,22]$.

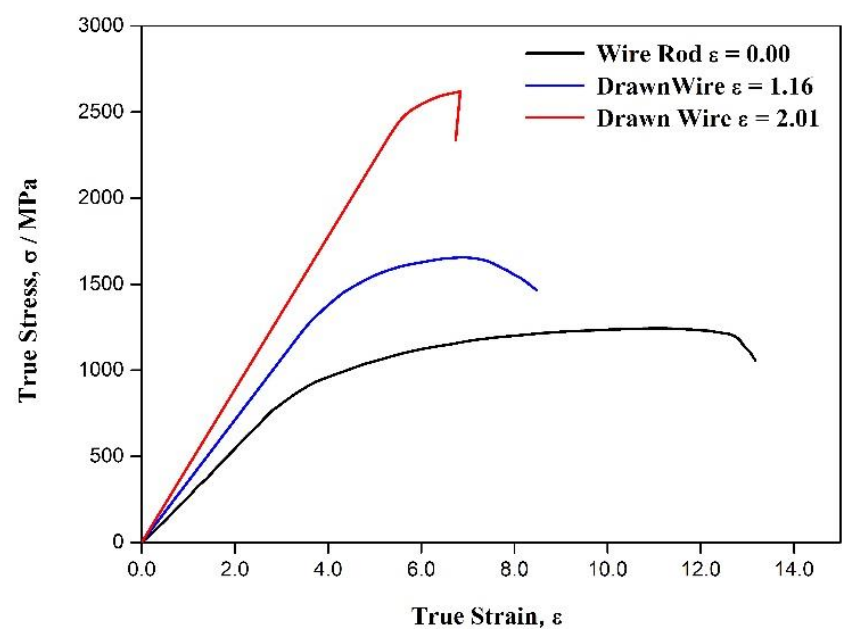

Fig. 3 stress-strain curves of the drawn pearlitic wires at a different 


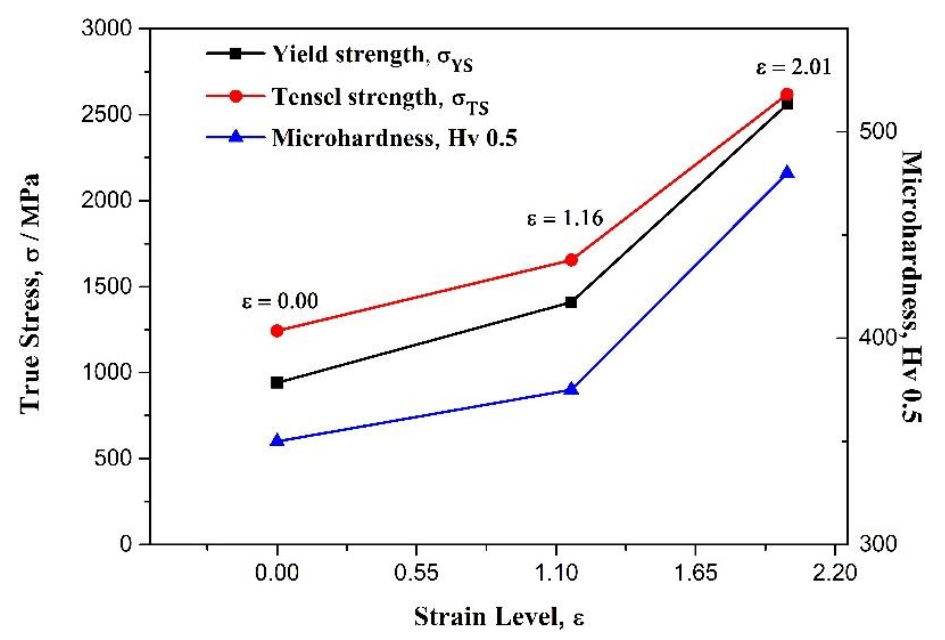

Fig. 4 Mechanical properties evolution as a function of drawing strain.

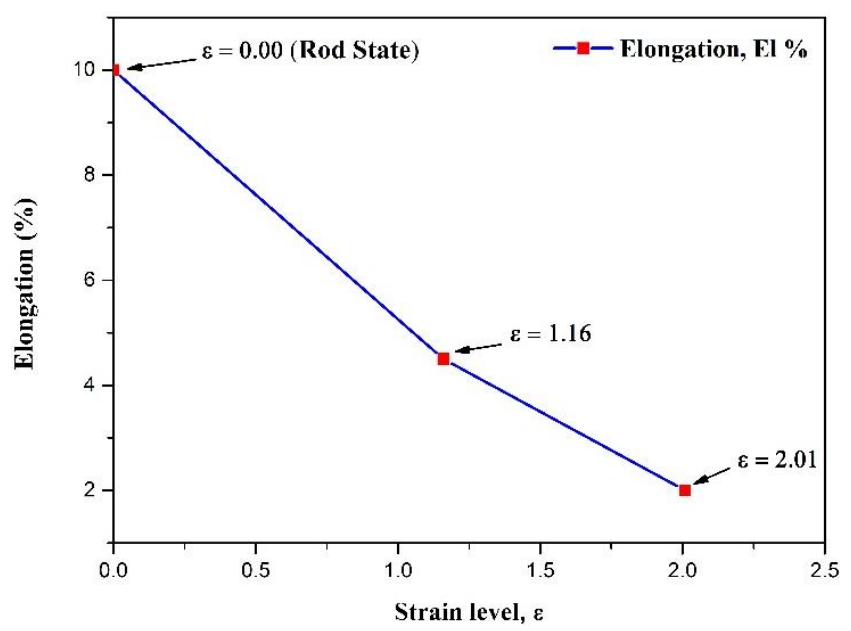

Fig. 5 Elongation evolution of the drawn pearlitic wires during

\subsection{Texture Evolution}

Figure 6 shows Major axis inverse pole figure EBSD coloring maps of the drawn steel wires. These coloring maps allowed us to display the texture evolution of wires under wire drawing. It can be seen that the rod state wire had almost equiaxed grains and random textures (Fig. 6a) leading to isotropic structure. As the drawing progresses, a $\langle 110\rangle$ fiber texture of the ferrite phase begins to develop gradually with deformation in the drawing direction as shown in fig. 6b-c. This takes the structure of the wire to change from isotropic to anisotropic. Numerous studies [12,19-21,26,29] have observed the same texture. For example, Guo et al. [2] in their study have investigated the texture evolution of drawn pearlitic steel wires in three regions including the middle, center, and surface of the wire. their results indicate the development of $\langle 110\rangle$ fiber texture of ferrite phase in all of those different regions.

The texture evolution in the ferrite phase of the drawn pearlitic wires with different levels of strain was presented in terms of $\{110\}$ inverse pole figure. Thus, the intensity of $\langle 110\rangle$ fiber texture of the wire rod and the drawn wires was quantified and presented in fig. 7. It can be seen that for the first case when the strain level $\varepsilon=1.16$, the max of the intensity of $\langle 110\rangle$ fiber texture increased rapidly and passed from 2.49 to 8.27 . This intensity of $\langle 110\rangle$ fiber texture increased more to reach 12.62 at higher deformation when $\varepsilon=2.01$ and became saturated. 
The same results were reported by Nebbar et al. [20] for drawn medium carbon steel wires but in their investigation the intensity of $\langle 110\rangle$ fiber texture increased and reached a value of 5.2 and 6.6 for $43.6 \%$ and $60 \%$ deformation levels, respectively. Compared to our study, the intensity of $\langle 110\rangle$ fiber texture was very remarkable for the same level of deformation.

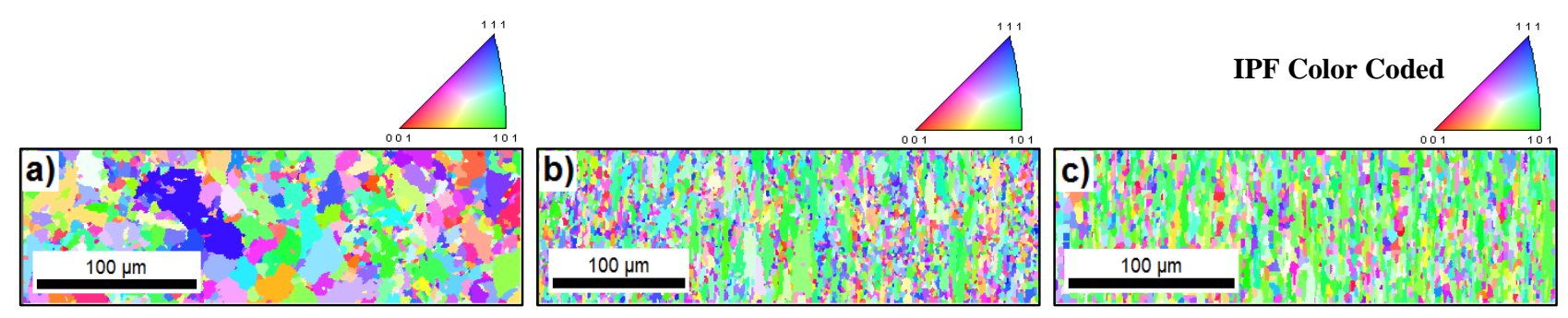

Fig. 6 Major axis inverse pole figure EBSD maps and IPF color-coded maps of the cold drawing pearlitic steel wires at different strain levels: a) $\varepsilon=0.00$ wire $\operatorname{rod}$ b) $\varepsilon=1.16$ c) $\varepsilon=2.01$

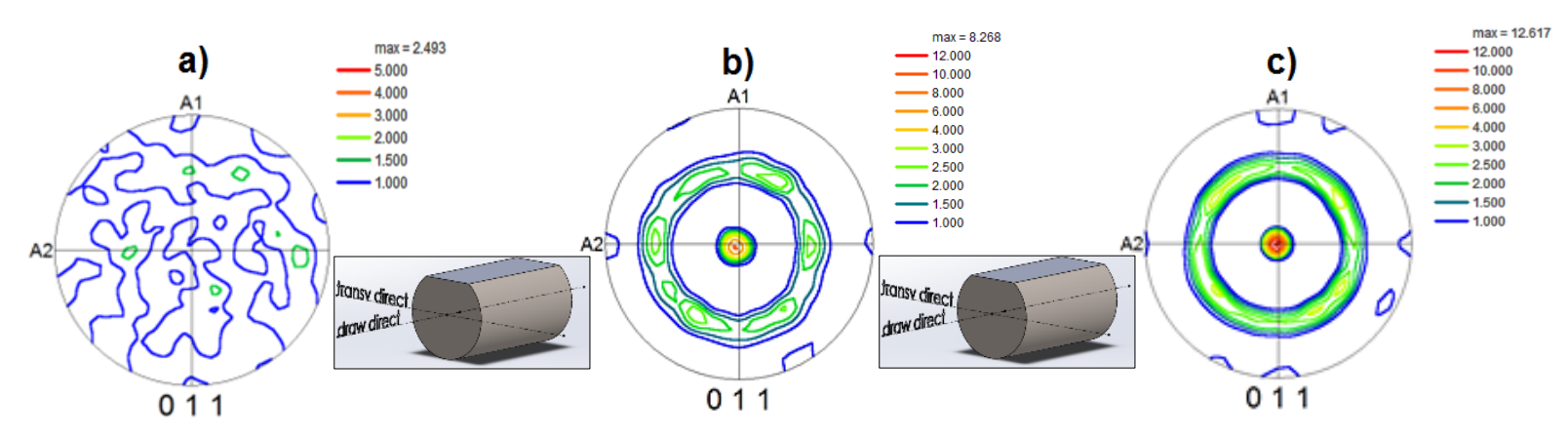

Fig. $7\{110\}$ inverse pole figure for ferrite phase of the cold drawing pearlitic steel wires at different strain levels: a) $\varepsilon=0.00$ (wire rod) $\quad$ b) $\varepsilon=1.16$ c) $\varepsilon=2.01$

\section{Conclusion}

Texture evolution and mechanical properties of cold drawn pearlitic steel wires are investigated in this paper. Based on the results, it can be concluded that :

- The results show that the wire rod had almost random textures resulting in isotropic structure. As the drawing proceeds, a strong <110> // ND fiber texture of ferrite phase forms and begins to develop gradually with deformation leading to a transformation of structure from isotropic to anisotropic. In addition, the quantitative analysis confirmed the results of micro-textures and shows that the maximum intensity of $\langle 110\rangle$ fibre texture increased more to reach 12.62 at higher deformation and became saturated.

- Experiences on drawn steel wires have shown that the wire drawing has a strong influence on these wires where tensile strength and $0,2 \%$ yield strength increased substantially with the strain level. While that reduced the elongation.

- Wire drawing induces the increase of dislocation density, reduction of interlamellar spacing and the refinement of grains size which leads to a strong hardening of the wires. 


\section{Acknowledgments}

This work is supported by the Algerian Ministry of Higher Education and Scientific Research and included as a part of PRFU project. The authors are very grateful to Trefesoud company (The National Company of Wire Drawing and Manufacture of Welding Products, Algeria) for supplying steel wires used in this investigation.

The authors would like also to acknowledge the technical team of exploitation division of Trefesoud company and the Thin Films and Applications Physics Laboratory (LPCMA) for their assistance and their contribution to conducting some of the experiments.

\section{References}

[1] A.M. Elwazri, P. Wanjara, S. Yue, The effect of microstructural characteristics of pearlite on the mechanical properties of hypereutectoid steel, Mater. Sci. Eng. A 404 (2005) 91-98.

[2] N. Guo, B. Luan, B. Wang, Q. Liu, Microstructure and texture evolution in fully pearlitic steel during wire drawing, Sci. China Technol. Sci. 56 (2013) 1139-1146.

[3] C. Borchers, R. Kirchheim, Cold-drawn pearlitic steel wires, Prog. Mater. Sci. 82 (2016) 405444.

[4] J. Languillaume, G. Kapelski, B. Baudelet, Cementite Dissolution in Heavily Cold Drawn, Acta Mater. 45 (1997) 1201-1212.

[5] O.P. Modi, N. Deshmukh, D.P. Mondal, A.K. Jha, A.H. Yegneswaran, H.K. Khaira, Effect of interlamellar spacing on the mechanical properties of 065\% C steel, Mater. Charact. 46 (2001) 347-352.

[6] S. Xiang, Y. He, W. Shi, X. Ji, Y. Tan, J. Liu, R.G. Ballinger, Chloride-induced corrosion behavior of cold-drawn pearlitic steel wires, Corros. Sci. 141 (2018) 221-229.

[7] L. Zhou, L. Wang, H. Chen, Z. Xie, F. Fang, Effects of Chromium Additions upon Microstructure and Mechanical Properties of Cold Drawn Pearlitic Steel Wires, J. Mater. Eng. Perform. 27 (2018) 3619-3628.

[8] F. Fang, L. Zhou, X. Hu, X. Zhou, Y. Tu, Z. Xie, J. Jiang, Microstructure and mechanical properties of cold-drawn pearlitic wires affect by inherited texture, Mater. Des. 79 (2015) 6067.

[9] S.S. Sahay, B.P. Gautham, Pearlitic Steels: Wire Drawing, Encycl. Iron, Steel, Their Alloy. (2016) 2501-2507.

[10] C. Schmitt, P. Lipinski, M. Berveiller, Micromechanical modelling of the elastoplastic behavior of polycrystals containing precipitates - Application to hypo- and hyper-eutectoid steels, Int. J. Plast. 13 (1997) 183-199.

[11] S. Goto, R. Kirchheim, T. Al-Kassab, C. Borchers, Application of cold drawn lamellar microstructure for developing ultra-high strength wires, Trans. Nonferrous Met. SOC. China 17 (2007) 1129-1138.

[12] M. Zidani, S. Messaoudi, T. Baudin, D. Solas, M.H. Mathon, Deformation textures in wire drawn perlitic steel, Int. J. Mater. Form. 3 (2010) 7-11. 
[13] S.K. Singh, B.P. Gautham, S. Goyal, A. Joshi, D. Gudadhe, Development of a virtual wire drawing tool for process analysis and optimization, Wire J. Int. 40 (2007) 81-87.

[14] M. Zidani, S. Messaoudi, F. Dendouga, T. Baudin, C. Derfouf, A. Boulagroun, M.H. Mathon, Study of the relation between microstructure and properties (mechanical/electrical) of copper wire drawing and annealed, Acta Phys. Pol. A 123 (2013) 470-472.

[15] J. Embrury, R. Fisher, The structure and properties of drawn pearlite, Acta Metall. 14 (1966) $147-159$.

[16] Y.S. Yang, J.S. Kang, J.G. Bae, C.G. Park, Nanostructure and torsional ductility of heavily cold drawn steel wires, Mater. Soc. Annu. Meet. 2 (2008) 181-186.

[17] D. Wei, L. Li, X. Min, F. Fang, Z. Xie, J. Jiang, Microstructure and mechanical properties of heavily cold drawn pearlitic steel wires: Effects of low temperature annealing, Mater. Charact. 153 (2019) 108-114.

[18] N. Guelton, M. Francois, Microstructure - Property Relationship in Cold-Drawn Pearlitic Steel Wires, Metall. Mater. Trans. A 51 (2019) 1543-1566.

[19] P. Kumar, N.P. Gurao, A. Haldar, S. Suwas, Progressive Changes in the Microstructure and Texture in Pearlitic Steel during Wire Drawing, Evolution (N. Y). 51 (2011) 679-684.

[20] M.C. Nebbar, M. Zidani, T. Djimaoui, T. Abid, Microstructural Evolutions and Mechanical Properties of Drawn Medium Carbon Steel Wire, Int. J. Eng. Res. Africa 41 (2019) 1-7.

[21] M. Zelin, Microstructure evolution in pearlitic steels during wire drawing, Acta Mater. 50 (2002) 4431-4447.

[22] X. Zhang, A. Godfrey, X. Huang, N. Hansen, Q. Liu, Microstructure and strengthening mechanisms in cold-drawn pearlitic steel wire, Acta Mater. 59 (2011) 3422-3430.

[23] Y. He, S. Xiang, W. Shi, J. Liu, X. Ji, W. Yu, Effect of microstructure evolution on anisotropic fracture behaviors of cold drawing pearlitic steels, Mater. Sci. Eng. A 683 (2017) 153-163.

[24] Y.S. Yang, J.G. Bae, C.G. Park, Nanostructure and mechanical properties of heavily colddrawn steel wires, Mater. Sci. Eng. A 508 (2009) 148-155.

[25] B. Hary, T. Guilbert, P. Wident, T. Baudin, R. Logé, Y. De Carlan, Investigation of the relationships between mechanical properties and microstructure in a Fe-9\% $\mathrm{Cr}$ ODS steel, EPJ Nucl. Sci. Technol 2 (2016) 1-8.

[26] T. Djimaoui, M. Zidani, M.C. Nebbar, T. Abid, H. Farh, A.L. Helbert, F. Brisset, T. Baudin, Study of microstructural and mechanical behavior of mild steel wires cold drawn at TREFISOUD, Int. J. Eng. Res. Africa 36 (2018) 53-59.

[27] S. Yamasaki, The microstructure and mechanical properties of drawn and aged pearlitic steel wires, Mater. Sci. Technol. 34 (2018) 1-11.

[28] G. Langford, Deformation of pearlite, Met. Trans A 8 (1977) 861-875.

[29] M. Zidani, M.C. Nebbar, T. Djimaoui, S. Messaoudi, et al, Mechanical behavior and texture evolution study of medium carbon steel wires during industrial wire-drawing process, in: Proc. 28th Int. Conf. Metall. Mater. Met. Brno, Czech Republic, EU,(2019) 344-348. 